\title{
Gastric cancer in East Azerbaijan, Iran: Five-year survival analysis of population-based cancer registry results
}

\author{
Pooneh Jabbaripour ${ }^{1}$, Mohammad Hossein Somi ${ }^{1 \oplus}$, Hossein Mashhadi Abdolahi ${ }^{2}$, Roya Dolatkhah ${ }^{3, *(0)}$
}

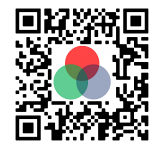

Use your smartphone to scan this QR code and download this article

${ }^{1}$ Liver and Gastrointestinal Diseases Research Center, Tabriz University of Medical Sciences, Tabriz, Iran

${ }^{2}$ Tabriz Health Services Management Research Center, Health Management and Safety Promotion Research Institute, Tabriz University of Medical Sciences, Tabriz, Iran

${ }^{3}$ Hematology and Oncology Research Center, Tabriz University of Medical Sciences, Tabriz, Iran

Correspondence

Roya Dolatkhah, Hematology and Oncology Research Center, Tabriz University of Medical Sciences, Tabriz, Iran

Email: royadoltakhah@yahoo.com

History

- Received: Sep 28, 2020

- Accepted: Nov 13, 2020

- Published: Nov 29, 2020

DOI : 10.15419/bmrat.v7i11.648

\section{Check for updates}

\section{Copyright}

(c) Biomedpress. This is an openaccess article distributed under the terms of the Creative Commons Attribution 4.0 International license.

\begin{abstract}
Introduction: Gastric cancer is the most common cancer with significant increasing trends during the last decade in Iran. The aim of this study was to evaluate the epidemiologic profile of gastric cancer along with gastric cancer-specific survival analysis. Methods: This was an analytical cross-sectional study in which all gastric cancer data were analyzed using the database of the East Azerbaijan Population-Based Cancer Registry (EA-PBCR). The incidents of definitive gastric cancer diagnosis were between the period of March $20^{\text {th }}, 2015$ to March $19^{\text {th }}, 2017$ ( = 3 Iranian solar years). The survival analysis was performed using the Kaplan-Meier method and life tables for 1- to 5-year survival data. The Log-rank test and Cox regression were computed to test the equality of survival function and mortality hazard. Results: Overall, 2,631 newly diagnosed gastric cancer cases were registered for 3 years. Gastric cancer was 2.35 times more common in men than women. The most common age group was the 7th decade- with 531 (31.2\%) gastric cancer cases. Most of the gastric cancer cases were non-cardia ( $n=2,244,85.29 \%)$ cancer, and the proportion of non-cardia to cardia gastric cancer was 5.8:1. Overall survival was 60.1\%, and 1- to 5-year survival proportions were $91.61 \%, 64.21 \%, 58.53 \%, 30.14 \%$ and $24.77 \%$, respectively. Cardia cancers had a worse survival rate than non-cardia cancers, and the hazard of mortality was 1.33 times higher in cardia than noncardia cancers (hazard ratio or $\mathrm{HR}=1.33 ; 95 \% \mathrm{Cl}$ : $1.05-1.68 ; \mathrm{P}=0.017$ ). Conclusion: Non-cardia gastric cancer is still the most dominant subsite in East Azerbaijan, Iran. There was a higher 1- to 5 -year survival proportion in East Azerbaijan, with lower overall mortality rates, compared to other regions of Iran.
\end{abstract}

Key words: Gastric Cancer, Cardia, Non-Cardia, Prognosis, East Azerbaijan

\section{INTRODUCTION}

The incidence of gastric cancer is particularly high in Iran, where it remains a leading cause of cancerrelated deaths. Gastric cancer is the most common cancer among Iranian men, with an age-standardized incidence rate (ASR) of 21.6 per 100,000 males, and is third among females (ASR $=9.44 / 100,000$ women $)^{1,2}$. The incidence and mortality of gastric cancer, by contrast, rank fifth and third, respectively, in both genders worldwide ${ }^{1}$.

Studies have shown that there has been an overall decrease of ASRs (between 2007 and 2017) by 6\% worldwide and for all socio demographic index (SDI) quintiles. Gastric cancer was the most common cancer in men compared to women, especially in highmiddle SDI countries, with 1 in 33 men and 1 in 78 women worldwide developing stomach cancer over a lifetime ${ }^{3}$.

Although the global incidence of gastric cancer has decreased in recent decades, in Iran as well ${ }^{4}$, there is still a high incidence of this cancer in the north and northwest regions of Iran compared to other regions of the country. Clustering the incidence of gastric cancer during 2004-2008 for the provincial-level, and in 2010 for the country-level, showed that the north and northwest of Iran are high-risk clusters ${ }^{4-6}$. The Ardebil Province in Northwest Iran has been introduced as a high-risk area- with the highest ASRs and age-standardized mortality rates (ASMRs) of gastric cancer $^{7-10}$. Moreover, there has been a six-fold difference in gastric cancer mortality rates between the northern and southern parts of Iran ${ }^{11}$. Recently, in the East Azerbaijan Province (located in the northwest of Iran), gastric cancer has become the most common cancer with significant increasing trends- by the overall annual percentage change (APC) statistical test- which showed $1.8 \%$ APC in both genders during the last decade, which was higher in men (APC, 3.2\%) than in women (APC, 1.3\%) $)^{12,13}$.

Since the incidence and mortality rates of gastric cancer have varied significantly in recent years in the different regions and provinces of $\operatorname{Iran}^{4,14,15}$, it is necessary to have an epidemiological study of the incidence, gender and age distribution, and morphological type of gastric cancer. The aim of this study was 
to evaluate the epidemiologic profile of gastric cancer, along with 1- to 5-year gastric cancer specific survival analysis, in cases from East Azerbaijan, Iran.

\section{METHODS}

\section{Data Sources}

All newly diagnosed cancer data were collected in EA-PBCR database, during the period of the $20^{\text {th }}$ of March 2015 to the $19^{\text {th }}$ of March 2017 (= 3 Iranian solar years), and from different data sources. The major sources of data collection related to the cancer cases were reports from pathology laboratories, hospital records, radiotherapy centers, and death registry databases.

The main demographic data, including the first and last name, national identification (NID) number, date of birth, date of diagnosis, gender, place of birth, and contact information were all recorded in the database. The morphology (including histology, behavior and grade of the cancer) and topography (primary site of the tumor) were coded and collected according to the International Classification of Disease for Oncology (ICD-O-3).

\section{Population}

This was an analytical cross-sectional study in which all gastric cancer data were analyzed using the database of the East Azerbaijan Population Based Cancer Registry (EA-PBCR), which included the definitive diagnoses of gastric cancer cases in the entire East Azerbaijan Province.

The East Azerbaijan Province is located in the northwest of Iran, and has a population of approximately 4 million people from the 20 counties, 62 cities, and 44 districts which comprise the largest Azeri Ethnic population in Iran.

\section{Quality Control}

Statistical data analysis, as well as quality and consistency checks, were performed to ensure clean and non-duplicated data. Most of the cases provided their address and contact information; follow-up and outcome data were obtained by contacting the patients' relatives and/or from the Hospital Information System (HIS).

\section{Statistical Analysis}

Gastric cancer-specific 1- to 5-year survival analysis and mortality rates were calculated using STATA MP 14.2 (Stata Corp LP, College Station, TX, USA). The survival status was considered from the date of diagnosis (as new cases were recorded in the EA-PBCR) to the date of gastric cancer-related death, and for censored cases until the last follow-up time. Patients were followed until the end of September 2019. The survival analysis was performed using the Kaplan-Meier method and life tables for 1- to 5-year survival data. The log-rank test and Cox regression analysis were used to test the equality of survival function and mortality hazard (HR, with 95\% CI) by age, gender, morphology, subsite, stage and grade.

\section{RESULTS}

\section{Study Sample}

We registered 2,631 new gastric cancer cases during 3 years: 918 (34.89\%) cases during 2015, 782 (29.72\%) during 2016, and 931 (35.39\%) during 2017. Of the cases, $1,849(70.19 \%)$ were males and $784(29.81 \%)$ were females; the male to female ratio was $2.35: 1$. The mean age of the patients was 67.52 (SD 12.77) years, with a range of 21-99 years. The most common age group was the $7^{\text {th }}$ decade- with 531 (31.2\%) cases having gastric cancer.

The most common morphological type was intestinal type adenocarcinoma $(n=1322,50.25 \%)$, followed by diffuse type AC ( $\mathrm{n}=677,25.73 \%)$. Of the cases, 387 (14.71\%) had cardia gastric cancer and 2,244 (85.29\%) had non-cardia gastric cancer; the proportion of noncardia to cardia was 5.8:1.

The stage of tumor was defined for 257 cases, whereby $53.70 \%$ of the cases $(n=138)$ were in stage II, and $27.63 \%$ of the cases were in stage III. The grade of cancer was available in 2,445 cases; of these, 384 (15.71\%) were grade I, 150 cases $(6.13 \%)$ were grade II, 253 cases $(10.35 \%)$ were grade III, and most of the cases $(\mathrm{n}=1,658,67.81 \%)$ were grade IV gastric cancer. The descriptive data are shown in Table 1.

\section{Survival Analysis}

Of the 2,631 cases, survival analysis was performed for 1,288 cases (we did not have access to contact information for the other 1,343 cases). From these, 514 (39.90\%) cases died and overall survival was $60.1 \%$ for the 5-year survival analysis. The 1-year to 5-year survival proportions were $91.61 \%, 64.21 \%, 58.53 \%$, $30.14 \%$ and $24.77 \%$, respectively. The overall mortality incidence rate was 17.19 per 100,000 people, and mean follow-up time was 23.22 (range of 6 - 36) months.

Log-rank test for equality of survival functions did not show any significant difference among cases $\leq 65$ years and $>65$ years $(\mathrm{P} \log$-rank $=0.881)$. There was not any significant difference of survival functions between males and females ( $\mathrm{P}$ log-rank $=0.959)$, but 
Table 1: Description of total cohort and cohort with follow-up N (\%) gastric cancer (2016-2018), unless specified otherwise

\begin{tabular}{|c|c|c|c|}
\hline & Characteristic & $\begin{array}{l}\text { Total Cohort } \\
(\mathrm{n}=\mathbf{2 , 6 3 1 )}\end{array}$ & $\begin{array}{l}\text { Cohort with Follow-up } \\
(\mathrm{n}=1,288)\end{array}$ \\
\hline \multirow[t]{4}{*}{ Age } & mean $( \pm S D)$ & $67( \pm 12.77)$ & $66.70( \pm 12.37)$ \\
\hline & range & $21-99$ & $26-97$ \\
\hline & $\leq 65$ years of age & $1,068(40.59 \%)$ & $557(43.25 \%)$ \\
\hline & $>65$ years of age & $1,563(59.41 \%)$ & $731(56.75 \%)$ \\
\hline \multirow[t]{2}{*}{ Sex } & Male & $1,847(70.20 \%)$ & $929(72.13 \%)$ \\
\hline & Female & $784(29.80 \%)$ & $359(27.87 \%)$ \\
\hline \multirow[t]{2}{*}{ Subsite } & Non-Cardia & $2,244(85.29 \%)$ & $1,027(79.74 \%)$ \\
\hline & Cardia & $387(14.71 \%)$ & $261(20.26 \%)$ \\
\hline \multirow[t]{3}{*}{ Morphology } & AC, Intestinal Type & $1322(50.25 \%)$ & $665(51.63 \%)$ \\
\hline & AC, Diffuse Type & $677(25.73 \%)$ & $380(29.50 \%)$ \\
\hline & Others & $632(24.02 \%)$ & $243(18.87 \%)$ \\
\hline \multirow[t]{5}{*}{ Grade } & I & $384(15.71 \%)$ & $171(13.32 \%)$ \\
\hline & II & $150(6.13 \%)$ & $112(8.72 \%)$ \\
\hline & III & $253(10.35 \%)$ & $213(16.59 \%)$ \\
\hline & IV & $1,658(67.81 \%)$ & $788(61.37 \%)$ \\
\hline & & Total $(\mathrm{n}=2,445)$ & Total $(\mathrm{n}=1,284)$ \\
\hline \multirow[t]{5}{*}{ Stage } & I & $46(17.90 \%)$ & 27 (13.99\%) \\
\hline & II & $138(53.70 \%)$ & $96(49.74 \%)$ \\
\hline & III & $47(18.29 \%)$ & $52(26.94 \%)$ \\
\hline & IV & $26(10.12 \%)$ & $18(9.33 \%)$ \\
\hline & & Total $(\mathrm{n}=257)$ & Total $(\mathrm{n}=193)$ \\
\hline
\end{tabular}

Table 2: Summary of statistics of 1,288 cases included in survival analysis during three years of study

\begin{tabular}{cccccc}
\hline $\begin{array}{c}\text { Years of } \\
\text { study }\end{array}$ & Case (percent) & $\begin{array}{c}\text { No. of subject } \\
(\%)\end{array}$ & $\begin{array}{c}\text { 5-Years Mortality rate/100,000 } \\
\text { people }\end{array}$ & $\begin{array}{c}\text { Overall } \\
\text { survival }\end{array}$ & $\begin{array}{c}\text { Mean } \\
\text { Overall } \\
\text { Survival }\end{array}$ \\
\hline 2015 & $182(14.13 \%)$ & $188(36.58 \%)$ & 66.69 & $0.00 \%$ & 14.99 \\
2016 & $463(35.95 \%)$ & $144(28.02 \%)$ & 10.58 & $68.9 \%$ & 29.37 \\
2017 & $643(49.92 \%)$ & $182(35.40 \%)$ & 13.58 & $70.8 \%$ & 21.11 \\
Total & 1288 & 514 & 17.19 & $60.1 \%$ & 23.22 \\
\hline
\end{tabular}

${ }^{*}$ failed cases

survival functions showed significant differences with respect to grade of tumor $(\mathrm{P}$ log-rank $=0.000)$ and stage of cancer $(\mathrm{P}$ Log-rank $=0.000)$, as higher stages and grades had worse survival functions. The morphological type of cancer did not have a significant effect on survival function ( $\mathrm{P} \log$-rank $=0.316$ ); however, cases with cardia tumors had worse survival than non-cardia tumors $(\mathrm{P} \log$-rank $=0.012)($ Figure 1$)$. Cox regression analysis at univariate level showed that the hazard of mortality was 1.33 times higher in cardia than non-cardia tumors ( $\mathrm{HR}=1.33$; $95 \% \mathrm{CI}$ : 1.05 1.68; $\mathrm{P}=0.017)$. In addition, higher stage and grade significantly increased the hazard of mortality compared with lower stage and grade. For example, HR
$=4.6$ (95\% CI: 3.83-5.67; $\mathrm{P}=0.000)$ for stage IV $v s$. stage I, and HR=6.06 (95\% CI: 3.40-10.81; P = 0.000) for grade IV $v s$. grade I.

At multivariate level, after adjusting all variables, regression analysis showed that grade of cancer significantly increased the HR, as HR in tumors with grade 4 was 2.36 times higher than those with grade 1 ( $\mathrm{HR}=$ 2.36; 95\% CI;0.95 - 5.87; P = 0.064). Those with grade 3 were 4.73 times higher than those with grade 1 (HR $=4.73 ; 95 \% \mathrm{CI}: 1.82-12.28 ; \mathrm{P}=0.001)$, and those with grade 2 had a HR of 2.47 (95\% CI: $0.75-8.14$ : P = $0.135)$ compared to those with grade 1 cancer. Age, gender, and morphological type did not impart any statistical differences among the groups with respect 


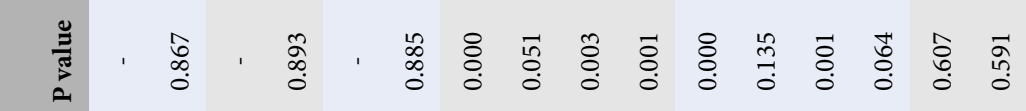

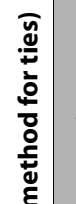

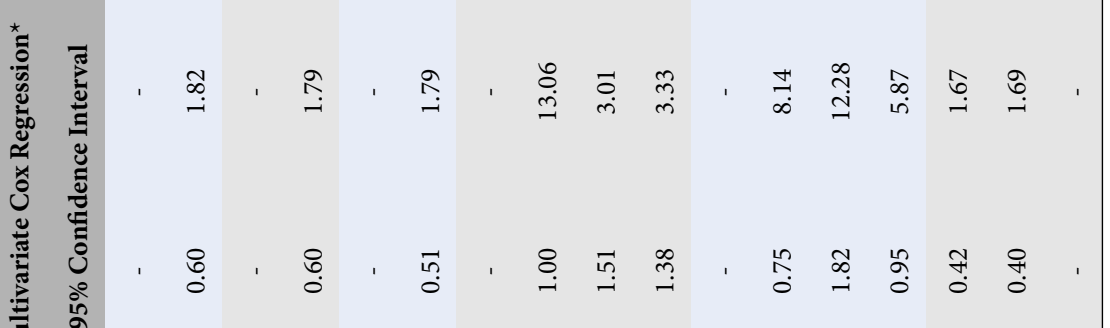

$\sum$

苂

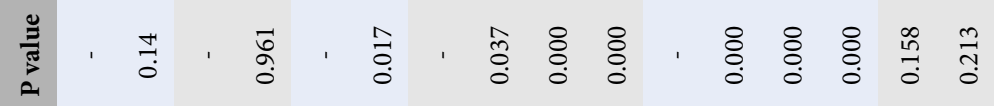

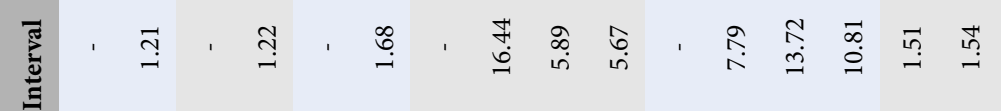

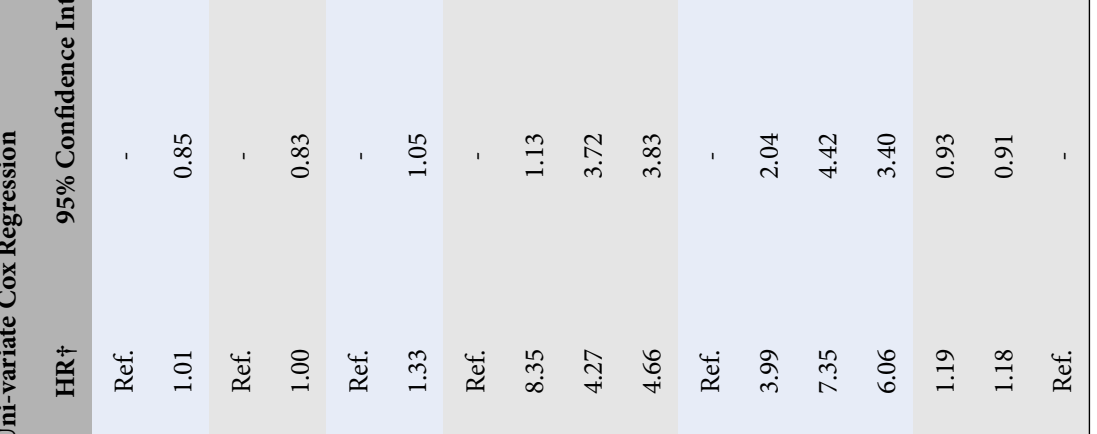

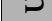

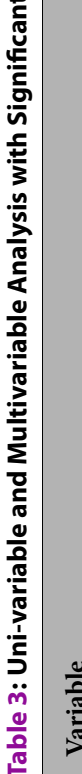

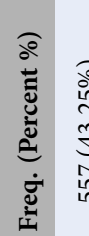

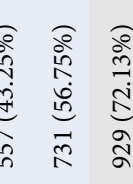

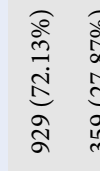

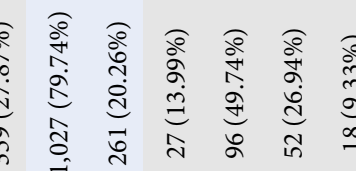

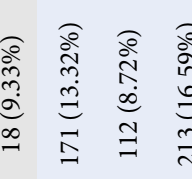

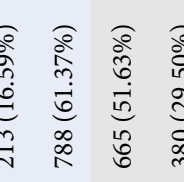

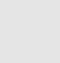

(n)

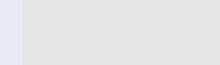


to mortality hazards. The results were presented in detail in Table 3.

\section{DISCUSSION}

According to the last published results of the EA$\mathrm{PBCR}$, gastric cancer was the most common cancer among men (ASR 29.7) and the third common in women (ASR 13.3). Therefore, we aimed to evaluate the epidemiologic profile of gastric cancer- along with 1- to 5-year gastric cancer specific survival analysis- in East Azerbaijan, the northwest region of Iran. During the 3 years of study, 2,631 newly diagnosed gastric cancer cases were registered in East Azerbaijan. The most common age group was the 7 th decadewith $531(31.2 \%)$ gastric cancer cases. Non-cardia gastric cancer frequency was markedly higher $(85 \%$ of cases), with $53.70 \%$ of cases in stage II and $67.81 \%$ with grade IV disease. The overall mortality incidence rate was 17.19 per 100,000 people, and the overall survival proportion was $60.1 \%$ - with mean followup time of 23.22 (range of 6 - 36) months for a 5year study. The 1 - to 5 -year survival proportions were $91.61 \%, 64.21 \%, 58.53 \%, 30.14 \%$ and $24.77 \%$, respectively. Cardia cancer had a 1.33-fold higher mortality hazard ratio than non-cardia cancer. Survival functions showed a significant difference with the grade of tumor $(\mathrm{P} \log$-rank $=0.000)$ and stage of cancer $(\mathrm{P} \log$ rank $=0.000)$, as higher stages and grades had worse survival functions.

According to the GLOBOCAN 2018 report, gastric cancer is the $5^{\text {th }}$ most common cancer and the $3^{\text {rd }}$ leading cause of cancer-related deaths, accounting for $8.2 \%$ of all cancer deaths worldwide ${ }^{1}$. Gastric cancer is the most common cancer among males- in terms of incidence and mortality- in Western Asian countries, including Iran, Turkmenistan, and Kyrgyzstan. The highest age-standardized incidence rates were reported in Korea for both genders ${ }^{1}$. Gastric cancer patients have an overall survival of about $90 \%$ in the early stages of disease; the 5-year survival proportions are $94 \%$ and $88 \%$ for stages IA and IB, respectively. However, in cases with advanced stage, the prognosis is poor. Recently, the average 5 -year survival rate was $31 \%$ in the United States, $19 \%$ in the United Kingdom, and $26 \%$ in Europe ${ }^{16,17}$. Gastric cancer is ranked as the leading cause of cancer-related deaths in Iran, accounting for $16.1 \%$ of cancer-related deaths. East Azerbaijan of Iran is a high-risk region of gastric cancer for both males and females ${ }^{7}$. Previous reports have revealed extremely high incidence and mortality rates for gastric cancer in East Azerbaijan, with gastric cancer being the $2^{\text {nd }}$ leading cause of death $(10.4 \%$ of all deaths) ${ }^{12,13,18}$.
The estimated gastric cancer specific AgeStandardized Mortality Rates (ASMRs) in 29 different provinces of Iran revealed extremely high mortality rates. There is a 6 -fold difference between the northern $(A S M R=29.1$ per 100,000) and southern $(A S M R=5.0$ per 100,000$)$ regions of Iran, with an average ASMR of 15 for males and 8.1 for females ${ }^{11}$. Iran is a large and geographically diverse country with several ethnic groups. Therefore, the variation in ASMRs and the high gastric cancer mortality rate in Iran may be linked to gene-environmental factors. However, different environmental risk factor exposures, including $H$. pylori infections and patterns, may also contribute to these variations. The overall 5-year mortality rate in our study was $\mathbf{1 7 . 1 9}$ per 100,000; this rate has been on a tremendous decline during the last decade. According to the results of a study by Zendehdel et al., the ASMR in Iran in 2012 was 27.6 per 100,000 in men (ranking as the $2^{\text {nd }}$ highest ASMR), and 13.6 per 100,000 in women (ranking as the $4^{\text {th }}$ highest ASMR) ${ }^{11}$.

Our results showed better 1- to 5-year survival proportions compared with previous reports from Iran ${ }^{19-22}$. According to other European reports, Iran still have lower survival rates than most developed countries $^{23}$. In our study, since more than half of the cases were in stage II of disease, and non-cardia gastric cancer was more common than cardia (85\% vs. $15 \%$ ), these results may have led to better prognosis. Cancers of the gastric cardia have epidemiological characteristics which are more similar to those of esophageal adenocarcinoma, and with poor prognosis; incidentally, the incidence of cardia cancers has been increasing, particularly in high-income countries $^{24,25}$. Evidence from previous studies have shown that the prognosis is better for non-cardia than cardia cancers ${ }^{26-28}$. There was a significant difference in survival function between cardia and non-cardia gastric adenocarcinoma in this study as well, with cardia cases having worse survival than non-cardia cases. Indeed, gastric cardia cancers had a 1.33-fold higher mortality hazard ratio than non-cardia cancers. Similar findings to ours have been reported in other studies conducted in Iran ${ }^{19-22}$.

Regardless of the overall incidence of gastric cancer, the proportion of non-cardia to cardia involvement in different population types seems to have different patterns ${ }^{7}$. Malekzadeh et al. emphasized this theory of higher rates of gastric cardia vs. non-cardia in the north and northwest regions of Iran, and vice versa for the south region and low risk areas of Iran, such as Khuzestan ${ }^{7}$. However, the results of our study showed an obvious higher incidence of non-cardia 

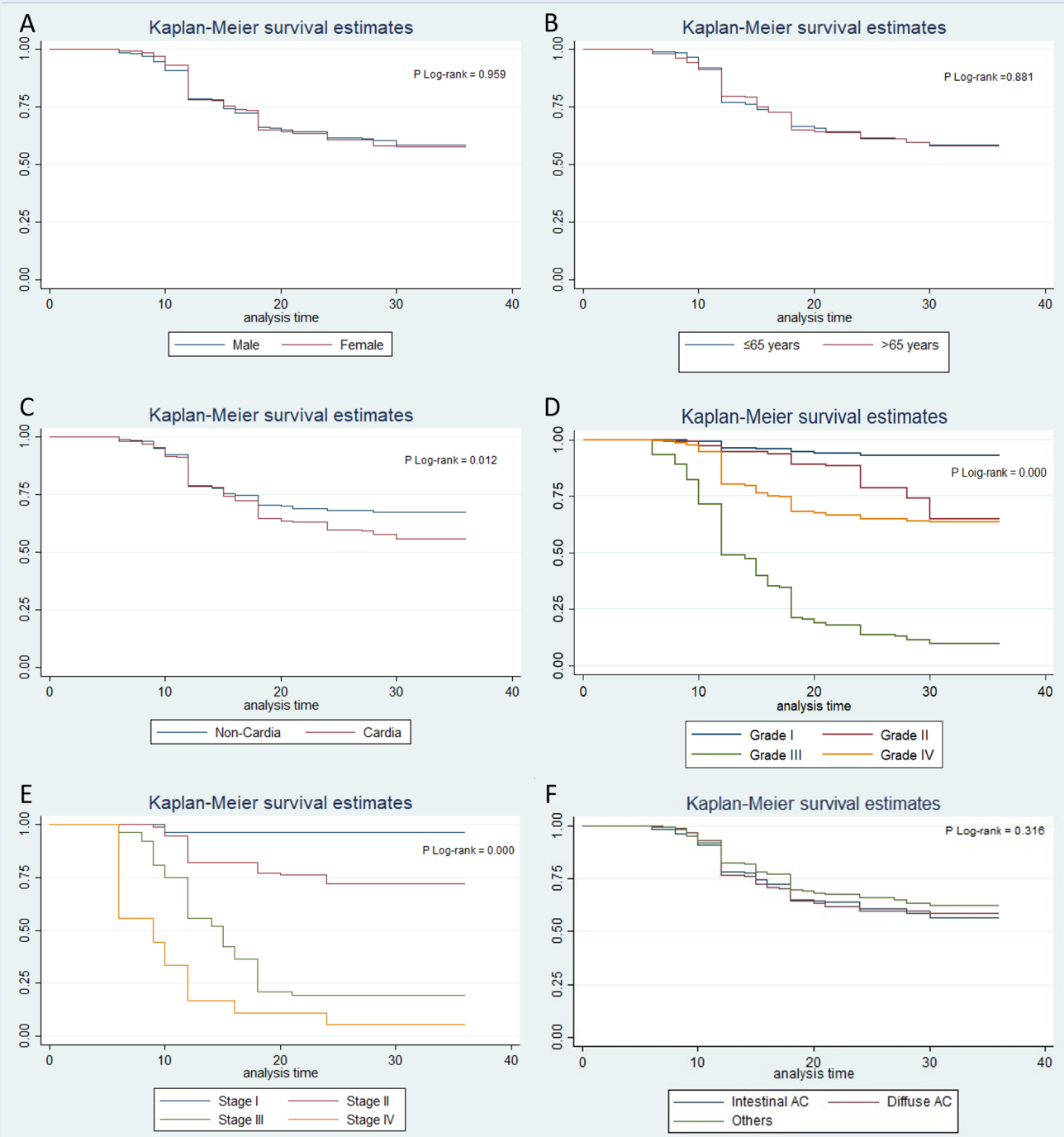

Figure 1: Kaplan-Meier survival curve results for the test of equality of gastric cancer-specific survival functions for the different variables in Northwest Iran with respect to: (A) gender, (B) age group, (C) subsite group, (D) grade, (E) stage, and (F) morphologic type.

cancers in East Azerbaijan; the 85\% prevalence of H. pylori infection in the East Azerbaijan population probably explains the higher incidence of non-cardia cancer in the present study ${ }^{29,30}$.

Gastric cancer is more common in men than women in most countries. The male to female ratio has ranged from 2.2:1 in developed countries, to $1.83: 1$ in developing countries ${ }^{16}$. In the present study, about $70 \%$ of gastric cases were males, and the male to female ratio was $2.35: 1$. Although the gastric cancer mortality rate is $2-3$ times higher in men than women ${ }^{1,31}$, there was no significant difference in survival function among genders in this study. While most other studies from
Iran have shown lower overall survival in males ${ }^{19,20}$, gender did not have any significant impact on mortality hazard of gastric cancer, according to the results of our study.

\section{STRENGTHS AND LIMITATIONS OF THE STUDY}

Population-based cancer registries are the best resources for epidemiological and surveillance systems and studies. In this study, we utilized one of the best and most reliable population-based cancer registry data in recent years. Indeed, the East Azerbaijan population-based cancer registry (EA-PBCR) has 
been established with high quality and timeliness in the region.

EA-PBCR is in its first step toward improving the quality indicators, including comparability, validity, timeliness, and completeness of cancer data. However, we performed the survival analysis only on approximately half of the registered gastric cancer cases in this study because we could not access the contact information of the others. Moreover, the stage of the disease is not a mandatory variable in the recent Iranian National Cancer Registry program; therefore, the stage was not available for most of gastric cancer cases. We hope to achieve better and more complete data concerning the stage and grade of cancers since a nationwide program has been recently instated in Iran for cancer staging, and is an ongoing plan at present.

\section{CONCLUSION}

In conclusion, non-cardia cancer is still the dominant subsite of gastric cancer in East Azerbaijan. However, we had higher 1- to 5- year survival proportions in East Azerbaijan, with improvement in mortality rates in the region. Additional studies of gastric cancer, particularly with respect to cancer subsite and cancer morphology, would be most informative.

\section{ABBREVIATIONS}

APC: Annual percentage change

ASMR: Age-standardized mortality rate

ASR: Age-standardized incidence rate

CI: Confidence Interval

EA-PBCR: East Azerbaijan Population-Based Cancer Registry

HR: Hazard Ratio

ICD-O: International Classification of Disease for Oncology

NID: National identification

OS: Overall Survival

SDI: Socio demographic index

\section{ACKNOWLEDGMENTS}

We would like to thank you from The East Azerbaijan Population Based Cancer Registry (EAPBCR) for providing the data of this study.

\section{AUTHOR'S CONTRIBUTIONS}

PJ, RD: substantial contributed to conception and design, acquisition of data, and analysis and interpretation of data; PJ, RD: drafting the article, and revised manuscript critically for important intellectual content; MHS, HMA: revised manuscript critically for important intellectual content. All authors read and approved the final manuscript.

\section{FUNDING}

This work was supported by Tabriz University of Medical Sciences as a confirmed research project [Grant number: 5/d/4876, 1395/2]; and Ministry of Health and Medical Education, Deputy of Research and Technology for manuscript submission (Grant number: 700/1480, 1395.10.4). The funding body didn't have any role in the design of the study and collection, analysis and interpretation of data and in writing the manuscript.

\section{AVAILABILITY OF DATA AND MATERIALS}

Data and materials used and/or analysed during the current study are available from the corresponding author on reasionable request.

\section{ETHICS APPROVAL AND CONSENT TO PARTICIPATE}

The East Azerbaijan Population Based Cancer Registry (EAPBCR) provided the data of this study. The ethics committee of Tabriz University of Medical Sciences has been approved this project, and all patients information and records are confidential (Grant Number: IR.TBZMED.REC.1395.1333). We followed ethics rules of EAPBCR for manuscript publication.

\section{CONSENT FOR PUBLICATION}

Not applicable.

\section{COMPETING INTERESTS}

The authors declare that they have no competing interests.

\section{REFERENCES}

1. Bray F, Ferlay J, Soerjomataram I, Siegel RL, Torre LA, Jemal A. Global cancer statistics 2018: GLOBOCAN estimates of incidence and mortality worldwide for 36 cancers in 185 countries. CA Cancer J Clin. 2018;68(6):394-424. PMID: 30207593. Available from: https://doi.org/10.3322/caac.21492.

2. Roshandel G, Ghanbari-Motlagh A, Partovipour E, Salavati F, Hasanpour-Heidari S, Mohammadi G, et al. Cancer incidence in Iran in 2014: Results of the Iranian National Populationbased Cancer Registry. Cancer Epidemiol. 2019;61:50-58. PMID: 31132560. Available from: https://doi.org/10.1016/j. canep.2019.05.009.

3. Global Burden of Disease Cancer $C$, Fitzmaurice $C$, Abate $D$, Abbasi N, Abbastabar H, Abd-Allah F, et al. Global, Regional, and National Cancer Incidence, Mortality, Years of Life Lost, Years Lived With Disability, and Disability-Adjusted Life-Years for 29 Cancer Groups, 1990 to 2017: A Systematic Analysis for the Global Burden of Disease Study. JAMA Oncol. 2019;5(12):1749-1768. Available from: 10.1001/jamaoncol. 2019.2996. 
4. Rastaghi S, Jafari-Koshki T, Mahaki B, Bashiri Y, Mehrabani K, Soleimani A. Trends and Risk Factors of Gastric Cancer in Iran (2005-2010). Int J Prev Med. 2019;10:79. PMID: 31198514. Available from: https://doi.org/10.4103/ijpvm.IJPVM_188_17.

5. Kavousi A, Bashiri Y, Mehrabi Y, Etemad K, Teymourpour A. Identifying high-risk clusters of gastric cancer incidence in Iran, 2004 - 2009. Asian Pac J Cancer Prev. 2014;15(23):1033510337. PMID: 25556471. Available from: https://doi.org/10. 7314/APJCP.2014.15.23.10335.

6. Karimi P, Islami F, Anandasabapathy S, Freedman ND, Kamangar F. Gastric cancer: descriptive epidemiology, risk factors, screening, and prevention. Cancer Epidemiol Biomarkers Prev. 2014;23(5):700-713. PMID: 24618998. Available from: https://doi.org/10.1158/1055-9965.EPI-13-1057.

7. Malekzadeh R, Derakhshan MH, Malekzadeh Z. Gastric cancer in Iran: epidemiology and risk factors. Arch Iran Med. 2009;12(6):576-583.

8. Abdi E, Latifi-Navid S, Zahri S, Yazdanbod A, Safaralizadeh R. Helicobacter pylori genotypes determine risk of non-cardia gastric cancer and intestinal- or diffuse-type GC in Ardabil: A very high-risk area in Northwestern Iran. Microb Pathog. 2017;107:287-292. PMID: 28390977. Available from: https: //doi.org/10.1016/j.micpath.2017.04.007.

9. Leylabadlo HE, Kafil HS, Yousefi M. Gastric cancer mortality in a high-incidence area (Ardabil Province, Northwest Iran): What risk factors are causative? Eur J Cancer Prev. 2016;25(6):573574. PMID: 27662226. Available from: https://doi.org/10.1097/ CEJ.0000000000000237.

10. Sadjadi A, Malekzadeh R, Derakhshan MH, Sepehr A, Nouraie $M$, Sotoudeh $M$, et al. Cancer occurrence in Ardabil: results of a population-based cancer registry from Iran. Int J Cancer. 2003;107(1):113-118. PMID: 12925965. Available from: https://doi.org/10.1002/ijc.11359.

11. Zendehdel K, Marzban M, Nahvijou A, Jafari N. Six-fold difference in the stomach cancer mortality rate between northern and southern Iran. Arch Iran Med. 2012;15(12):741-746.

12. Somi MH, Dolatkhah R, Sepahi S, Belalzadeh M, Naghashi S, Asghari Jafarabadi M. A 12-year trend analysis of the incidence of gastrointestinal cancers in East Azerbaijan: last updated results of an ongoing population-based cancer registry. BMC Cancer. 2019;19(1):782. PMID: 31391032. Available from: https://doi.org/10.1186/s12885-019-6008-3.

13. Somi MH, Dolatkhah R, Sepahi S, Belalzadeh M, Sharbafi J, Abdollahi $L$, et al. Cancer incidence in the East Azerbaijan province of Iran in 2015-2016: results of a population-based cancer registry. BMC Public Health. 2018;18(1):1266. PMID: 30453968. Available from: https://doi.org/10.1186/s12889018-6119-9.

14. Moradzadeh R, Anoushirvani AA. Trend of Gastric Cancer Incidence in an Area Located in the Center of Iran: 2009-2014. J Gastrointest Cancer. 2020;51(1):159-164. PMID: 30911981. Available from: https://doi.org/10.1007/s12029-019-00227-8.

15. Moradzadeh R, Nadrian $\mathrm{H}$, Najafi A. Trend of gastric cancer in a province in Western Iran: A population-based study during 2001-2014. J Res Med Sci. 2020;25:12. PMID: 32174984. Available from: https://doi.org/10.4103/jrms.JRMS_262_19.

16. Rawla P, Barsouk A. Epidemiology of gastric cancer: global trends, risk factors and prevention. Prz Gastroenterol. 2019;14(1):26-38. PMID: 30944675. Available from: https: //doi.org/10.5114/pg.2018.80001.

17. Feng Q, May MT, Ingle S, Lu M, Yang Z, Tang J. Prognostic Models for Predicting Overall Survival in Patients with Primary Gastric Cancer: A Systematic Review. Biomed Res Int. 2019;2019:5634598. PMID: 31641669. Available from: https: //doi.org/10.1155/2019/5634598.
18. Somi MH, Golzari M, Farhang S, Naghashi S, Abdollahi L. Gastrointestinal cancer incidence in East Azerbaijan, Iran: update on 5 year incidence and trends. Asian Pac J Cancer Prev. 2014;15(9):3945-3949. PMID: 24935578. Available from: https://doi.org/10.7314/APJCP.2014.15.9.3945.

19. Karimi JM, Gholami A, Cheragian B, Abolghasemi J, Solaymani-dodaran M, Madani AH, et al. Survival rate of patients with gastric cancer. Med J Islam Repub Iran. 2019;33:74. PMID: 31696068. Available from: https://doi.org/10.47176/mjiri.33.74.

20. Akhondi-Meybodi M, Ghane M, Akhondi-Meybodi S, Dashti G. Five-year Survival Rate for Gastric Cancer in Yazd Province, Central Iran, from 2001 to 2008. Middle East J Dig Dis. 2017;9(1):39-48. PMID: 28316765. Available from: https: //doi.org/10.15171/mejdd.2016.50.

21. Movahedi M, Afsharfard A, Moradi A, Nasermoaddeli A, Khoshnevis J, Fattahi F, et al. Survival rate of gastric cancer in Iran. J Res Med Sci. 2009;14(6):367-373.

22. Veisani Y, Delpisheh A. Survival rate of gastric cancer in Iran; a systematic review and meta-analysis. Gastroenterol Hepatol Bed Bench. 2016;9(2):78-86.

23. Pabla BS, Shah SC, Corral JE, Morgan DR. Increased Incidence and Mortality of Gastric Cancer in Immigrant Populations from High to Low Regions of Incidence: A Systematic Review and Meta-Analysis. Clin Gastroenterol Hepatol. 2020;18(2):347359-e5. PMID: 31154030. Available from: https://doi.org/10. 1016/j.cgh.2019.05.032.

24. Colquhoun A, Arnold M, Ferlay J, Goodman KJ, Forman D, Soerjomataram I. Global patterns of cardia and non-cardia gastric cancer incidence in 2012. Gut. 2015;64(12):18811888. PMID: 25748648. Available from: https://doi.org/10. 1136/gutjnl-2014-308915.

25. Lagergren $\mathrm{F}$, Xie SH, Mattsson F, Lagergren J. Updated incidence trends in cardia and non-cardia gastric adenocarcinoma in Sweden. Acta Oncol. 2018;57:1173-1178. PMID: 29600886. Available from: https://doi.org/10.1080/0284186X. 2018.1457797.

26. Asplund J, Kauppila JH, Mattsson F, Lagergren J. Survival Trends in Gastric Adenocarcinoma: A Population-Based Study in Sweden. Ann Surg Oncol. 2018;25(9):2693-2702. PMID: 29987609. Available from: https://doi.org/10.1245/s10434018-6627-y.

27. Ghidini M, Donida BM, Totaro L, Ratti M, Pizzo C, Benzoni I, et al. Prognostic factors associated with survival in a large cohort of gastric cancer patients resected over a decade at a single Italian center: the Cremona experience. Clin Transl Oncol. 2020;22:1004-1012. PMID: 31599376. Available from: https://doi.org/10.1007/s12094-019-02220-w.

28. Cao X, Cao D, Jin M, Jia Z, Kong F, Ma H, et al. CD44 but not CD24 expression is related to poor prognosis in noncardia adenocarcinoma of the stomach. BMC Gastroenterol. 2014;14(157). PMID: 25212506. Available from: https://doi. org/10.1186/1471-230X-14-157.

29. Ghotaslou R, Milani M, Akhi MT, Nahaei MR, Hasani A, Hejazi MS, et al. Diversity of Helicobacter Pylori cagA and vacA Genes and Its Relationship with Clinical Outcomes in Azerbaijan, Iran. Adv Pharm Bull. 2013;3(1):57-62.

30. Hosseini E, Poursina F, de Wiele TV, Safaei HG, Adibi P. Helicobacter pylori in Iran: A systematic review on the association of genotypes and gastroduodenal diseases. J Res Med Sci. 2012;17(3):280-292.

31. Casamayor M, Morlock R, Maeda H, Ajani J. Targeted literature review of the global burden of gastric cancer. Ecancermedicalscience. 2018;12:883. PMID: 30679950. Available from: https://doi.org/10.3332/ecancer.2018.883. 